\title{
Inmunogenicidad, inocuidad y eficacia de una vacuna tetravalente obtenida por recombinación genética de rotavirus aislados de monos rhesus y seres humanos en Belém, Brasil ${ }^{1}$
}

\author{
A. C. Linhares, ${ }^{2}$ Y. B. Gabbay, ${ }^{2}$ J. D. P. Mascarenhas, ${ }^{2}$ R. B. de Freitas, ${ }^{2}$ C. S. \\ Oliveira, ${ }^{2}$ N. Bellesi, ${ }^{3}$ T. A. F. Monteiro, ${ }^{2}$ Zéa Lins-Lainson, ${ }^{2}$ F. L. P. Ramos ${ }^{2}$ y S. A. \\ Valente $^{2}$
}

RESUMEN Se evaluó la inocuidad, inmunogenicidad y eficacia de una vacuna tetravalente obtenida por recombinación genética de rotavirus aislados de monos rhesus y seres humanos (RRV-TV) $\left(4 \times 10^{4}\right.$ unidades formadoras de placas por dosis) en un ensayo prospectivo, aleatorio, a doble ciego y controlado con placebo que se efectuó con 540 lactantes brasileños. Se administraron dosis de vacuna o de placebo a la edad de 1, 3 y 5 meses. No se observaron diferencias significativas en la frecuencia de diarrea o vómito en los bebés de ninguno de los dos grupos después de administrar la dosis correspondiente. De 2 a 3\% de los vacunados tuvieron fiebre baja los días tercero a quinto después de recibir la primera dosis, pero no después de las dosis segunda o tercera. Se observó una respuesta de anticuerpos del tipo IgA al rotavirus aislado de monos rhesus (RRV) en 58\% de los vacunados y en 33\% de quienes recibieron placebo. La respuesta de anticuerpos neutralizantes a cada serotipo no pasó de $20 \%$ cuando se determinó con la prueba de reducción de focos de fluorescencia, pero fue superior a $40 \%$ al medirse con la prueba de neutralización a base de reducción de placas.

Se presentaron 91 casos de diarrea causada por rotavirus entre los niños que recibieron las tres dosis (de vacuna o de placebo) durante un seguimiento de 2 años, 36 de ellos en los niños vacunados. La eficacia general de la vacuna fue de $8 \%(\mathrm{P}=0,005)$ contra toda clase de diarrea y de $35 \%(\mathrm{P}=0,03)$ contra la diarrea causada por rotavirus. La protección durante el primer año de seguimiento, cuando predominó el rotavirus $G$ del serotipo 1, fue de $57 \%$ ( $\mathrm{P}=0,008)$, pero se redujo a $12 \%$ en el segundo año. Se obtuvieron resultados similares al restringir el análisis a episodios en que el rotavirus fue el único agente patógeno identificado. Se observó en la vacuna una mayor tendencia a proteger contra casos de enfermedad con un promedio de seis o más deposiciones diarias. Estos resultados son lo suficientemente alentadores para justificar que en países en desarrollo se hagan otros estudios de esta vacuna con una dosis mayor para tratar de mejorar su inmunogenicidad y eficacia.

1 Se publicó en inglés en el Bulletin of the World Health Organization, Vol. 74, No. 5, 1996, con el título "Immunogenicity, safety, and efficacy of tetravalent rhesus-human reassortant rotavirus vaccine in Belém, Brazil". (c) Organización Mundial de la Salud, 1996.

2 Instituto Evandro Chagas, Av. Almirante Barroso 492, 66.090-000 Belém, Pará, Brasil. La correspondencia debe dirigirse a A. C. Linhares a esta direc-
ción.
Los rotavirus causan más de 125 millones de casos de diarrea infantil y alrededor de 1 millón de defunciones

\footnotetext{
3 Clínica de Medicina Preventiva de Pará (CLIMEP), Belém, Pará, Brasil.
}

anuales en el mundo, sobre todo en zonas tropicales (1). A juzgar por la similitud de su incidencia en países industrializados y en desarrollo, la enfermedad no se controlará con mejores prácticas de abastecimiento de agua, saneamiento o higiene y es evi- 
dente que se necesita una vacuna efi$\operatorname{caz}(2,3)$.

Las estrategias para preparar una vacuna oral comprenden desde el "método de Jenner", con cepas de rotavirus aisladas de animales, hasta la aplicación de técnicas de biología molecular (4). Un método prometedor consiste en producir cepas recombinantes de rotavirus aislados de seres humanos y de animales con la especificidad de neutralización de las cepas humanas, con el objetivo de provocar inmunidad homotípica contra cada uno de los cuatro serotipos importantes del rotavirus $G(5,6)$.

Los ensayos efectuados en Finlandia y Estados Unidos de América con vacunas obtenidas de un solo serotipo rotavírico aislado de monos rhesus y seres humanos $(7,8)$ han demostrado que se obtiene protección después de administrar una sola dosis de $10^{4}$ unidades formadoras de placas (ufp). La protección, que no fue necesariamente específica para cada serotipo, duró más de 1 año, fue mayor en lactantes que mostraron una respuesta de anticuerpos de tipo $\operatorname{Ig} \mathrm{A}$ en suero a la vacuna y fue quizá mayor en episodios de diarrea graves que en episodios leves. En Finlandia, por ejemplo, donde prevalecía el serotipo 1 del rotavirus $\mathrm{G}$, las tasas de protección conferidas por las vacunas obtenidas de rotavirus aislados de monos rhesus y seres humanos con especificidad para el serotipo 1 del rotavirus $G(D \times$ vacuna contra rotavirus aislados de monos rhesus (RRV)) o del serotipo 2 $(\mathrm{DS} 1 \times \mathrm{RRV})$ alcanzaron un promedio de 66 y 38\%, respectivamente, en los períodos primero y segundo de la epidemia de infección por rotavirus después de la inmunización (7). En lactantes con una respuesta de anticuerpos de tipo IgA en suero, esas cifras fueron de 92 y 59\%, respectivamente. En cambio, la eficacia de la vacuna en los países en desarrollo ha sido desalentadora. En un ensayo de 2 años efectuado en el Perú (9), ni la vacuna $\mathrm{D} \times \mathrm{RRV}$ ni la DS1 $\times$ RRV, administradas en una sola dosis, confirieron mucha protección contra la diarrea causada por rotavirus heterotípicos $u$ homotípicos.
Las iniciativas más recientes se han dirigido hacia la evaluación de la vacuna tetravalente contra RRV (RRVTV), que contiene específicamente cepas recombinantes de rotavirus aislados de monos rhesus y seres humanos de los serotipos 1, 2 y 4 del rotavirus $G$ y de RRV del serotipo 3 del rotavirus $G$, con la esperanza de que confiriera protección particular contra cada uno de los cuatro serotipos importantes de rotavirus $G$ y una mayor protección general que cada uno de los elementos por separado. Se han evaluado la inocuidad e inmunogenicidad de las vacunas a base de cepas recombinantes de RRV, administradas solas o en combinación a niños y lactantes (10-17). Sin embargo, solo hay datos limitados sobre la eficacia de la vacuna RRV-TV. En los Estados Unidos se logró un grado de protección de $57 \%$ contra la diarrea causada por rotavirus durante un período de 2 años, después de aplicar tres dosis de la vacuna (cada una de $4 \times 10^{4}$ unidades formadoras de placas) (18). En cambio, en el Perú tres dosis de la vacuna proporcionaron una protección de solamente $24 \%$ por 1 año (19).

El presente estudio se realizó para determinar la inocuidad, inmunogenicidad y eficacia de tres dosis de la vacuna RRV-TV en lactantes sanos en Belém, Brasil.

\section{MATERIALES Y MÉTODOS}

En el trabajo sobre el terreno hemos seguido esencialmente las recomendaciones de Lanata y Black (20). El estudio fue autorizado por el Comité de Ética del Instituto Evandro Chagas, el Consejo Regional de Medicina, la Secretaría de Salud Pública del Estado de Pará y el Ministerio de Salud del Brasil y por el Comité de Ética de la OMS.

Zona del estudio y su población. Belém se encuentra en el Norte del Brasil, cerca de la desembocadura del río Amazonas, y tiene un clima tropical húmedo. La mitad de su población, que está estimada en 1,5 millones de habitantes, vive en condiciones de hacinamiento y con sistemas de saneamiento deficientes. El ensayo se realizó en una zona de $8 \mathrm{~km}^{2}$ con una población de 350000 habitantes. Según estudios anteriores en esa zona, los rotavirus ocasionan alrededor de $30 \%$ de los casos de diarrea aguda en lactantes y niños pequeños hospitalizados (21) y casi $10 \%$ de los episodios de gastroenteritis aguda en la comunidad (22). Los cuatro serotipos del rotavirus $\mathrm{G}$ circulan en la zona y el tipo 1 es el más común (23).

Se reunió a un total de 1064 mujeres embarazadas por medio de visitas domiciliarias realizadas entre octubre de 1989 y enero de 1990 y de ese total se seleccionó a 540 mujeres para participar en el ensayo. Se procuró agrupar a las familias por zona geográfica con objeto de facilitar el trabajo de campo. Desde su reclutamiento y hasta el momento del parto, se hicieron visitas mensuales a las mujeres para mantener activo su interés y reiterar los objetivos y condiciones del estudio. Asimismo se dieron charlas sobre el proyecto periódicamente en los centros comunitarios.

Se inscribió a los lactantes durante la primera visita mensual después del nacimiento y en la misma ocasión se solicitó a los padres de familia que firmaran el formulario de consentimiento fundamentado. Se excluyó a los lactantes del estudio cuando $a$ ) los padres no habían dado su consentimiento, b) los niños tenían alguna enfermedad crónica o c) algún miembro de la familia estaba tomando un medicamento inmunosupresor o tenía algún tipo de inmunodeficiencia. De febrero a septiembre de 1990 se reunió a 540 recién nacidos, la mayoría (94\%) de marzo a julio.

Diseño del estudio. El estudio fue un ensayo de 2 años aleatorio, prospectivo, a doble ciego, controlado con placebo, en el que los lactantes recibieron tres dosis de placebo o de la vacuna RRV-TV. Se administraron las dosis primera, segunda y tercera a 540, 513 y 495 lactantes, respectivamente, a una edad aproximada de 1, 3 y 5 meses 
(recorridos de edad: 30-59, 90-119 y 150-179 días, respectivamente). Se tomó sangre venosa a 180 niños antes de administrar la primera dosis y se recolectaron 170, 168 y 165 especímenes de los mismos niños un mes después de aplicarles las dosis primera, segunda y tercera, respectivamente. Se congelaron las muestras de suero a $-20{ }^{\circ} \mathrm{C}$ hasta que fueron sometidas a ensayos detectores de anticuerpos antirrotavíricos.

El tamaño muestral se calculó según lo recomendado por Lanata y Black (20). El estudio se diseñó con el propósito de detectar una eficacia protectora mínima de $70 \%$ (con un nivel alfa de $5 \%$ y una potencia de $90 \%$ ) contra todos los episodios de diarrea causada por rotavirus durante los 2 años de vigilancia después de la inmunización. La incidencia esperada en el grupo tratado con placebo se basó en lo que se había observado durante la vigilancia previa en la misma zona (22). Al cabo del seguimiento hacía falta un mínimo de 200 niños por grupo. Se hizo una selección aleatoria por grupos de doce manzanas empleando los números consecutivos de la inscripción de los niños: se seleccionaron 180 niños al azar para estudios de inmunogenicidad a razón de tres niños vacunados por cada niño tratado con placebo. La aplicación aleatoria de la vacuna y la selección de los niños para el estudio de inmunogenicidad estuvieron a cargo de la empresa de laboratorios Wyeth-Ayerst de Radnor, Pensilvania, Estados Unidos de América. El código de la vacuna se guardó en la oficina de los laboratorios Wyeth-Ayerst y en la OMS y no se reveló hasta después de terminada la vigilancia: se verificaron y corrigieron los datos y se confirmó el carácter definitivo de los datos finales.

La vacuna y la inmunización. Cada dosis de la vacuna RRV-TV contenía 4 $\times 10^{4}$ ufp con partes iguales de a) la cepa recombinante del serotipo G1 $(\mathrm{D} \times \mathrm{RRV}), \mathrm{b})$ la cepa recombinante del serotipo G2 (DS1 $\times$ RRV), c) la cepa del serotipo G3 del RRV y d) la cepa recombinante del serotipo G4 $(\mathrm{ST} 3 \times \mathrm{RRV})$. Cada cepa recombinante contenía la codificación genética del antígeno VP7 del rotavirus G de los serotipos 1, 2 ó 4 aislados de seres humanos, y los 10 genes restantes se derivaban de la cepa MMU18006 de rotavirus aislados de monos rhesus (4). La vacuna y el placebo (exudado de un cultivo celular sin infección) fueron fabricados por los laboratorios Wyeth-Ayerst, se suministraron liofilizados y se mantuvieron a $4{ }^{\circ} \mathrm{C}$ hasta que se usaron. Los viales de vacuna $y$ placebo se numeraron en serie y eran idénticos en su apariencia. Los viales para los niños preseleccionados aleatoriamente para el estudio de inmunogenicidad tenían rótulos rosados distintivos. Se reconstituyeron con 1,2 mL de agua destilada inmediatamente antes de su administración.

De abril de 1990 a enero de 1991, se administró la vacuna o el placebo dos veces a la semana en el Instituto Evandro Chagas. Cada niño fue examinado por un pediatra antes de la inmunización. Se reprogramó la vacunación de los niños que habían tenido fiebre o diarrea en las últimas 48 ó 72 horas, respectivamente. Se dejó de amamantar o de alimentar con biberón al niño una hora antes y después de la inmunización. Inmediatamente antes de ella, se dieron a cada niño $30 \mathrm{~mL}$ de leche evaporada reconstituida ( $\sin$ actividad neutralizante antirrotavírica y con $400 \mathrm{mg}$ de bicarbonato de sodio). También se sacaron por venipuntura de 2 a $5 \mathrm{~mL}$ de sangre a los lactantes incluidos en el estudio de inmunogenicidad. Se instó a las madres a obtener otras vacunas de administración obligatoria de los servicios oficiales de salud pública. Sin embargo, según el acuerdo logrado con las autoridades locales de salud pública, nuestro personal asumió la responsabilidad de administrar la vacuna antipoliomielítica oral a todos los participantes. Esta se dio un mínimo de 15 días antes o después de aplicarse la vacuna antirrotavírica.

Vigilancia de efectos secundarios y de episodios de diarrea. Después de la inmunización, se visitó a cada niño diariamente durante 7 días consecuti- vos. En cada visita se observaron y registraron los siguientes datos: a) número y consistencia de las deposiciones en las últimas 24 horas; b) frecuencia del vómito; c) temperatura rectal y d) presencia de síntomas respiratorios. A partir del séptimo día después de administrar la primera dosis y por un período de 2 años, se visitó a cada niño a domicilio dos veces a la semana para observar cualquier episodio de diarrea, definida como tres o más deposiciones líquidas o semilíquidas en un período de 24 horas. En los casos en que se detectó diarrea se hicieron visitas diarias hasta el final del episodio, es decir, hasta cuando el niño hubiera tenido menos de tres deposiciones líquidas o semilíquidas en cada período de 24 horas por un período de 2 días o más. Durante los episodios de diarrea se registraron periódicamente los siguientes parámetros clínicos: a) número de deposiciones en cada período de 24 horas (incluidas las de consistencia acuosa); b) duración de la diarrea; c) presencia de sangre o moco en las deposiciones; d) frecuencia del vómito; e) fiebre determinada por la vía rectal; y f) signos de deshidratación según los criterios establecidos por la OMS (24). Cuando hubo signos de deshidratación, un médico de nuestra plantilla visitó al niño y lo remitió a un servicio médico o a un hospital público, según fuese necesario.

Procedimientos de laboratorio. Se obtuvieron muestras de materia fecal o frotis rectales lo más pronto posible después de detectar un episodio de diarrea. Se recolectaron especímenes durante el episodio y por un período de 48 horas después de su desaparición. Durante 1990 y 1991 se recogieron solamente muestras de materia fecal; en 1992 se tomaron frotis rectales cuando no fue posible obtener una muestra de heces. Las heces o los frotis rectales se colocaron en solución salina estéril para examen de rotavirus y en dos viales con tapa de rosca con el medio de Cary-Blair, uno de los cuales contenía un suplemento antimicrobiano de Skirrow (25). También se 
colocó una muestra en un frasco lleno de una solución de Merthiolate, yodo $y$ formalina para hacerle examen parasitológico. Las muestras se trasladaron al laboratorio en las siguientes 4 horas en cajas forradas de material aislante y cargadas de paquetes fríos y se examinaron el mismo día. Todas se sometieron metódicamente a medición de antígenos antirrotavíricos con estuches de inmunoensayo enzimático (ELISA) de marca DAKOPATTS (Copenhague, Dinamarca) (26). Se determinó el serotipo de las cepas de rotavirus $\mathrm{G}$ con anticuerpos monoclonales, siguiendo básicamente la técnica descrita por Taniguchi et al. (27). Los resultados se confirmaron en el Departamento de Higiene y Epidemiología de la Facultad de Medicina de Sapporo, Japón. Las cepas de rotavirus cuyo serotipo no se pudo identificar por este método se determinaron en el Instituto de Enfermedades Infecciosas de la Universidad de Pavía, Italia, con microscopía inmunoelectrónica de fase sólida (28).

Solo las muestras fecales positivas a rotavirus se examinaron posteriormente, usando las técnicas establecidas, para determinar la presencia de otros agentes patógenos causantes de diarrea (29). La producción de enterotoxinas por Escherichia coli se examinó mediante el uso de estuches comerciales: la toxina termolábil con la prueba de aglutinación pasiva inversa en látex (VET-RPLA, Unipath Ltd., Basingstoke, Hampshire, Reino Unido) y la toxina termoestable con una prueba ELISA de marca competitiva (estuche de inmunoensayo enzimático para la toxina termoestable de E. coli, Unipath Ltd., Basingstoke, Hampshire, Reino Unido). Además, todas las bacterias E. coli enteropatógenas identificadas en este estudio (con procedimientos serológicos normales) se sometieron a pruebas adicionales para determinar la presencia del factor de enteroadherencia (FEA) con sonda genética, como se indicó antes (30). Las muestras fecales positivas a rotavirus se examinaron en todos los casos con técnicas convencionales de análisis parasitológico y para determinar la presencia de Cryptosporidium sp., usando un método de tinción modificado a base de los colorantes de Ziehl-Nielsen y auramina (31).

Las muestras de suero tomadas antes y después de la inmunización se sometieron a pruebas detectoras de anticuerpos antirrotavíricos en los United Medical Laboratories (McLean, Virginia, EUA). Se determinó la concentración de anticuerpos de tipo IgA contra rotavirus con un inmunoensayo enzimático que utiliza RRV como antígeno de captación, según se explicó anteriormente $(32,33)$. Todas las muestras de suero tomadas de un mismo sujeto se examinaron simultáneamente, comenzando con una dilución de 1:50. Se determinó la presencia de anticuerpos neutralizantes contra serotipos específicos de rotavirus con un ensayo modificado de fluorescencia y reducción de focos (FRF) (34). Todos los sueros se analizaron para determinar la presencia de anticuerpos contra los serotipos G1 (cepa Wa), G2 (cеpa DS1), G3 (сера P), G4 (cеpa ST3) y RRV. También se determinó la concentración de anticuerpos neutralizantes contra las cepas WA, DS1, SC2 (cepa recombinante de G2 basada en WC3), RRV, WI78-8 (tipo G3) y BrB9 (cepa recombinante de G4 basada en WC3) en el suero de 20 personas vacunadas con RRV-TV con la prueba de neutralización a base de reducción de placas (NRP), esencialmente de la forma descrita en otros trabajos (35).

Análisis de datos. Un total de 495 (92\%) de los 540 lactantes a quienes se administró la primera dosis de vacuna o de placebo recibieron inmunización completa. De esos 495, 466 (94\%) tuvieron un seguimiento que duró el total de los 2 años que duró el estudio. Hubo pérdidas al seguimiento por defunción (8 niños), retiro del consentimiento (1 niño) y emigración de la zona de estudio (65 niños). Al determinar la eficacia de la vacuna, se tuvieron en cuenta solo los episodios de diarrea que se presentaron no menos de 15 días después de administrarse la tercera dosis de vacuna o placebo. Se excluyeron del análisis los niños que no habían recibido inmunización completa. Se calculó la eficacia de la vacuna en términos de episodios de diarrea positivos a rotavirus y de episodios de infección "pura" por rotavirus, es decir, sin la identificación de ningún otro agente enteropatógeno (Salmonella, Shigella, Aeromonas sp., Campylobacter sp., Vibrio sp., E. coli enterotoxígena, E. coli positiva al FEA, Cryptosporidium sp., Giardia intestinalis o Entamoeba histolytica). También se evaluó la eficacia contra indicadores de la gravedad clínica (GC) según un sistema de calificación modificado de 20 puntos propuesto por Flores et al. (36).

La eficacia de la vacuna y los intervalos de confianza de $95 \%$ se determinaron de la manera descrita anteriormente (20). Se analizaron las diferencias entre el grupo que recibió vacuna y el que recibió placebo, aplicando para ello la prueba de asociación de ji al cuadrado de MantelHaenszel o la prueba exacta de Fisher, según lo indicado (se consideró significativo un valor $P<0,05$ ).

\section{RESULTADOS}

Reactogenicidad. La vacuna RRVTV fue bien tolerada. Las incidencias de diarrea y vómito durante los 7 días posteriores a las dosis primera, segunda y tercera, y de fiebre después de las dosis segunda y tercera no mostraron diferencia significativa entre quienes recibieron la vacuna y el placebo. De 1,6 a 2,9\% de los lactantes tuvieron fiebre baja (temperatura rectal $\geq 38{ }^{\circ} \mathrm{C}$ ) entre los días tercero y quinto después de recibir la primera dosis de la vacuna RRV-TV, pero eso se observó solo en 0,4 a 1,2\% de los niños que recibieron placebo $(P<0,05$ en la prueba del ji al cuadrado).

Serología. Se tomaron muestras de suero antes de la vacunación y después de la tercera dosis a 161 lactantes (40 niños que recibieron placebo y 121 que recibieron la vacuna). Los resultados de la seroconversión determinada con el ELISA detector de IgA y con la prueba detectora de anticuerpos neutralizantes [con FRF], después de administrar tres dosis, se resumen en 
la figura 1. La seroconversión detectada por aumento de los anticuerpos de tipo IgA en la prueba ELISA fue mucho más frecuente $(P=0,005)$ entre los vacunados (58\%) que entre los lactantes que recibieron placebo (33\%). En cambio, entre los vacunados las tasas de seroconversión específicas de cada serotipo medidas por la presencia de anticuerpos neutralizantes detectados por FRF fueron menores de $20 \%$, con excepción de la respuesta a RRV (la seroconversión fue de 62 y $7,5 \%$, respectivamente, en el grupo vacunado y el tratado con placebo, $P<0,001)$. Se observaron diferencias significativas entre estos dos grupos solamente en el caso del serotipo 2 (19\% frente a $5 \%, P=0,03)$ y de los cuatro serotipos humanos combinados ( $18 \%$ frente a $2,5 \%, P=0,01)$. La media geométrica de los títulos (MGT) de anticuerpos neutralizantes contra los serotipos 1, 2, 3 y 4 del rotavirus G también fueron bajos y en el grupo vacunado alcanzaron un valor máximo de 62 contra la combinación de serotipos humanos. Por contraste, la MGT de los anticuerpos contra el RRV fue de 410 y 24 en ambos grupos, respectivamente $(P<0,005)$.

En el cuadro 1 se resumen las respuestas de anticuerpos a los serotipos G1-4 de rotavirus después de cada dosis de la vacuna RRV-TV, según la prueba de neutralización a base de reducción de placas (NRP). Antes de la inmunización las tasas de seropositividad a todos los tipos y cepas de rotavirus G, excepto a la cepa G2/SC2-9, fueron mayores de $60 \%$. Además, las tasas de respuesta serológica después de cualquiera de las dosis oscilaron entre 45 y $75 \%$ con las cepas G1/WA y G3/RRV, respectivamente.

Eficacia protectora. Durante el período de seguimiento (que comenzó 15 días después de la tercera dosis), de julio de 1990 a junio de 1992, hubo 264363 días-niño de vigilancia, y ello corresponde a 724 años-niño. En el caso particular de los grupos que recibieron placebo y vacuna hubo $363 \mathrm{y}$ 361 años-niño de observación, respectivamente. Se registró un total de 4197
FIGURA 1. Tasas de seroconversión en lactantes que han recibido inmunización completa. La seroconversión se define como un aumento del cuádruplo o más de la respuesta de anticuerpos de tipo IgA detectada con ELISA o de anticuerpos neutralizantes detectados con FRF en una comparación entre muestras de suero tomadas antes de la inmunización y otras muestras tomadas un mes después de administrar la tercera dosis de vacuna o placebo. ST indica el serotipo que indujo la respuesta de anticuerpos neutralizantes. Las comparaciones estadísticas se resumen en el texto

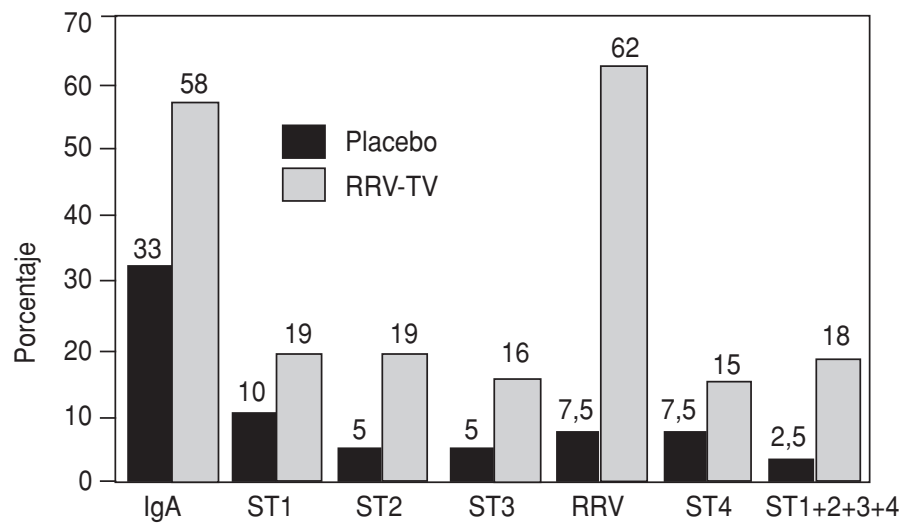

episodios de diarrea, con tasas de 6,0 y 5,6 episodios por año-niño en los tratados con placebo y vacuna, respectivamente. Por ende, la eficacia de la vacuna contra cualquier enfermedad diarreica fue de $8 \%$ al cabo de 2 años (IC95\%: $3 \%$ a $13 \% ; P=0,005$ ).

Se analizaron muestras de materia fecal o frotis rectales en 1990 episodios de diarrea ( $48 \%$ del total) con ELISA, a fin de determinar la presencia de antígenos antirrotavíricos. En total se detectaron 131 episodios de diarrea

por rotavirus durante el período de estudio y de ellos, 91 comenzaron a los 15 días o más después de administrada la tercera dosis (figura 2). Por ende, se detectaron rotavirus en $4,6 \%$ de los episodios de diarrea (91 de los 1990 casos), ya fuera como único agente patógeno o en asociación con otros agentes enteropatógenos. Cuando se toman los tres años en conjunto, las tasas de incidencia de diarrea por rotavirus durante el período de julio a septiembre fueron mucho

CUADRO 1. Respuestas serológicas, para cada serotipo específicoa, observadas en niños que recibieron la vacuna RRV-TV, según la prueba de neutralización a base de reducción de placas

\begin{tabular}{|c|c|c|c|c|c|}
\hline \multirow[b]{2}{*}{ Tipos/cepas G } & \multirow{2}{*}{$\begin{array}{c}\begin{array}{c}\text { No. de sueros } \\
\text { positivos/No. de } \\
\text { sueros examinados }\end{array} \\
\begin{array}{c}\text { Antes de la } \\
1 .^{\text {a }} \text { dosis }\end{array}\end{array}$} & \multicolumn{4}{|c|}{ No. de respuestas serológicas/No. de sueros examinados } \\
\hline & & $\begin{array}{l}\text { Después de } \\
\text { la 1. }{ }^{\text {a }} \text { dosis }\end{array}$ & $\begin{array}{l}\text { Después de } \\
\text { la } 2 .^{\text {a }} \text { dosis }\end{array}$ & $\begin{array}{l}\text { Después de } \\
\text { la } 3 .^{\text {a }} \text { dosis }\end{array}$ & $\begin{array}{l}\text { Después de } \\
\text { cualquier dosis }\end{array}$ \\
\hline G1/WA & $15 / 20(75)^{b}$ & $3 / 20$ (15) & $4 / 20(20)$ & $3 / 20(20)$ & 9/20 (45) \\
\hline G2/DS1 & 15/20 (75) & 4/19 (21) & 4/20 (20) & 3/20 (15) & 10/19 (53) \\
\hline G2/SC2-9 & 6/20 (30) & $5 / 20(25)$ & $6 / 20(30)$ & $5 / 20(25)$ & 13/18 (72) \\
\hline G3/RRV & $16 / 20(80)$ & $8 / 20(40)$ & $7 / 20$ (35) & $4 / 20(20)$ & 15/20 (75) \\
\hline G3/WI78-8 & $14 / 19(74)$ & $3 / 20(15)$ & $7 / 20(35)$ & $3 / 20(35)$ & $12 / 20(60)$ \\
\hline G4/BrB9 & $11 / 18(61)$ & $2 / 20$ (10) & $6 / 20(30)$ & $5 / 20(25)$ & $11 / 20(55)$ \\
\hline
\end{tabular}


FIGURA 2. Distribución mensual de 91 casos de diarrea rotavírica entre los sujetos que participaron en el estudio de julio de 1990 a junio de 1992. Los casos son los que se iniciaron un mínimo de 15 días después de administrar la tercera dosis de vacuna o placebo

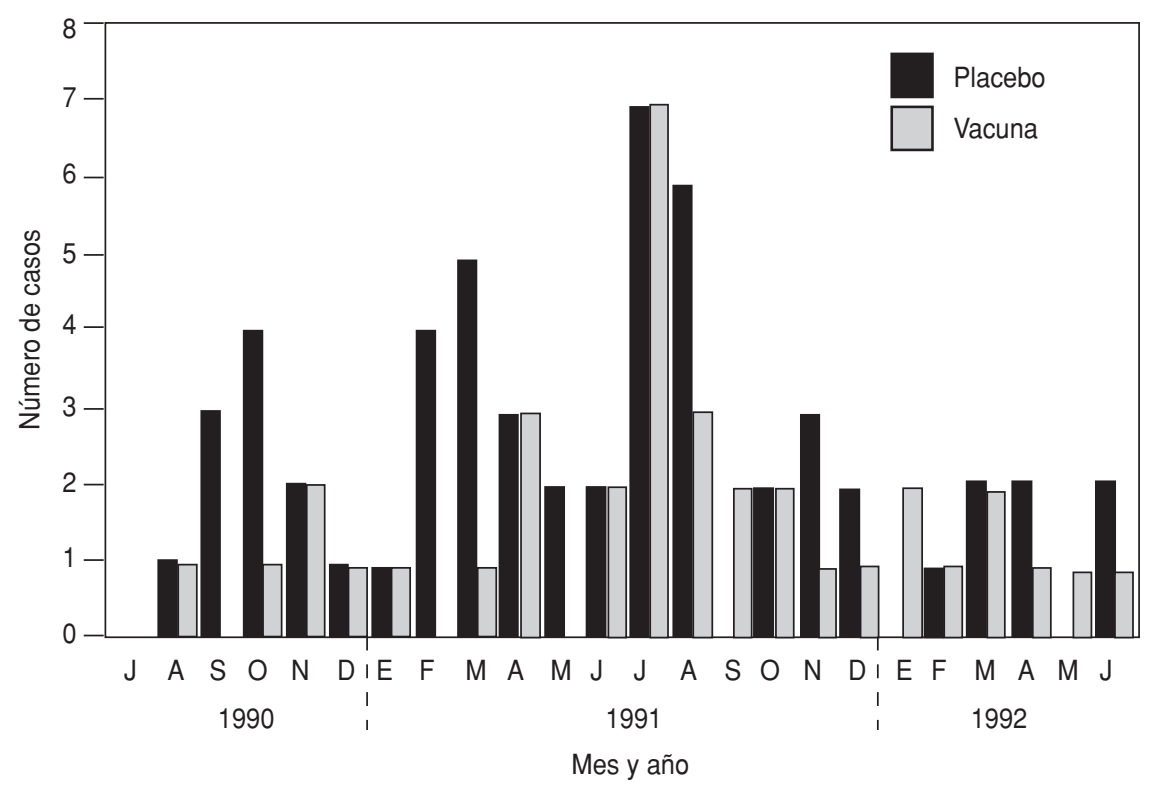

mayores $(P=0,0007)$ que durante el resto del año (figura 3). Las infecciones mixtas representaron $30 \%$ de los casos cuando se incluyeron G. intestinalis y E. coli enteropatógena (ECEP) defini-

das solamente por presencia de antisueros específicos contra el grupo O. Sin embargo, al excluir a Giardia y analizar solo las cepas de ECEP positivas al factor de enteroadherencia, la pro-

FIGURA 3. Tasas mensuales de incidencia de diarrea rotavírica entre los sujetos que participaron en el estudio de julio de 1990 a junio de 1992. Los casos son los que se iniciaron un mínimo de 15 días después de administrar la tercera dosis de vacuna o placebo

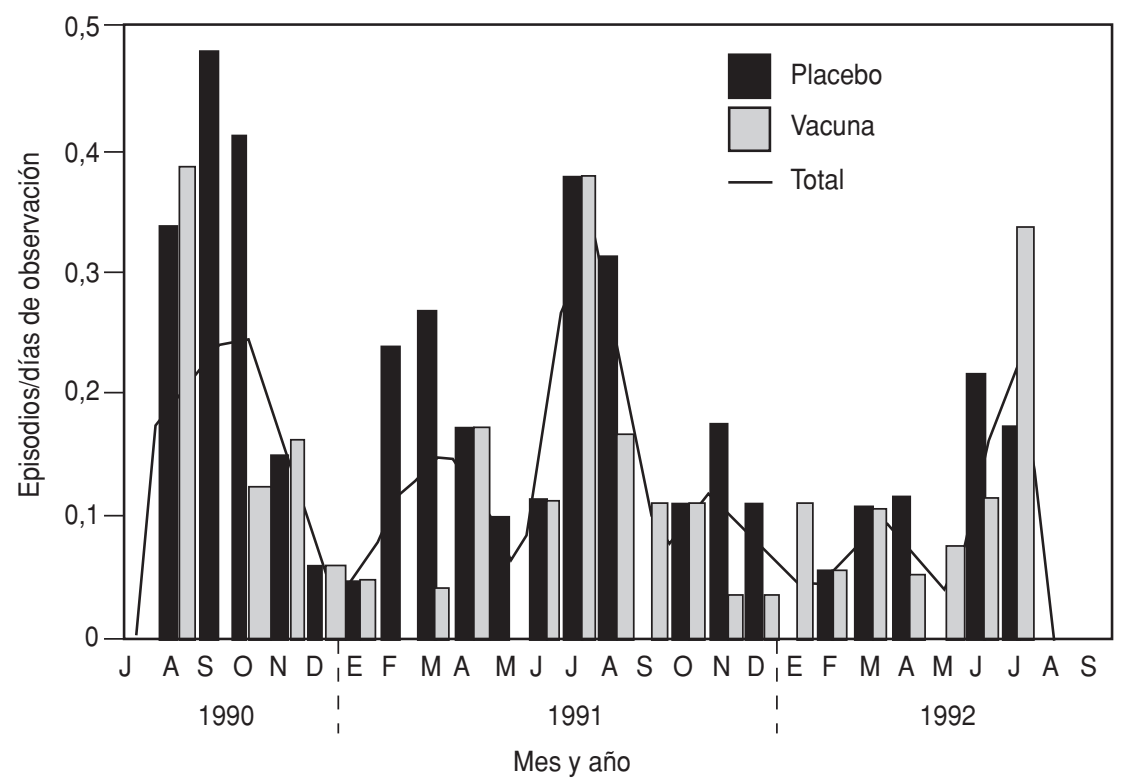

porción de infecciones mixtas fue de $18 \%$. Esta última definición de infección mixta se ha empleado para análisis de eficacia. Se pudieron serotipificar $86(94 \%)$ de las 91 cepas de rotavirus. Los serotipos G1, 2, 3, 4 y 9 representaron $65 \%(58 / 86), 30 \%$ $(24 / 86), 1,2 \%(1 / 86), 4,6 \%(4 / 86)$ y $1,2 \%(1 / 86)$ de las cepas cuyo serotipo se identificó, respectivamente.

En el cuadro 2 se resume la eficacia protectora de la vacuna RRV-TV contra todos los episodios de diarrea y contra los episodios "puros" de diarrea por rotavirus y por los serotipos 1 ó 2 . Se presentaron 55 y 36 episodios de infección por rotavirus en los grupos que recibieron placebo y vacuna, respectivamente. Ello significa que la vacuna tiene una eficacia general de $35 \%$ por un período de 2 años contra todos los tipos de diarrea provocados por rotavirus $(P=0,03$, prueba de ji al cuadrado; IC95\%: 2 a 56\%). La eficacia protectora contra los episodios puros de diarrea causada por rotavirus fue de $37 \%$ al cabo de 2 años $(P=0,04$; IC95\%: 1 a $59 \%$ ).

Durante el primer año de seguimiento (julio de 1990 a junio de 1991), la vacuna tuvo una eficacia de más de $50 \%$ contra todos los episodios de diarrea causados por rotavirus y contra los provocados por el serotipo 1 . No fue posible determinar la protección contra los episodios causados por el serotipo 2 debido a la escasez de casos. Durante el segundo año de seguimiento la vacuna no confirió ninguna protección contra diarreas causadas por rotavirus del serotipo 1. Se observó un grado de protección moderado contra la enfermedad causada por el serotipo 2, pero no fue estadísticamente significativo.

La protección conferida por la vacuna medida en términos de los indicadores específicos de gravedad clínica en los niños con diarrea de origen rotavírico se resume en los cuadros 3 y 4 . Como indica el cuadro 3, durante los 2 años de seguimiento la vacuna RRV-TV confirió 47\% $(P=0,02)$ y $58 \%(P=0,03)$ de protección contra un número máximo de deposiciones líquidas (MDL) $\geq 6$ y un número medio de deposiciones líquidas $(\mathrm{mDL}) \geq 6$ en 
CUADRO 2. Eficacia protectora de la vacuna tetravalente RRV contra todos los casos de diarrea y contra los casos puros producidos por serotipos rotavíricos específicos

\begin{tabular}{|c|c|c|c|c|}
\hline $\begin{array}{l}\text { Episodios de diarrea rotavírica, } \\
\text { por año de seguimiento }\end{array}$ & $\begin{array}{c}\text { Número } \\
\text { tratado } \\
\text { con placebo }\end{array}$ & $\begin{array}{c}\text { Número } \\
\text { tratado } \\
\text { con vacuna }\end{array}$ & $\begin{array}{l}\text { Porcentaje de } \\
\text { protección }\end{array}$ & $P^{a}$ \\
\hline $\begin{array}{l}\text { Dos años } \\
\text { (7/90-6/92): }\end{array}$ & $(363)^{b}$ & (361) & & \\
\hline $\begin{array}{l}\text { Todos los casos } \\
\text { Casos puros causados por RV }\end{array}$ & $\begin{array}{l}55 \\
46\end{array}$ & $\begin{array}{l}36 \\
29\end{array}$ & $\begin{array}{l}35 \\
37\end{array}$ & $\begin{array}{l}0,03 \\
0,04\end{array}$ \\
\hline $\begin{array}{l}\text { Todos los casos causados por RV ST1 } \\
\text { Casos puros causados por RV ST1 }\end{array}$ & $\begin{array}{l}32 \\
27\end{array}$ & $\begin{array}{l}24 \\
19\end{array}$ & $\begin{array}{l}25 \\
29\end{array}$ & $\begin{array}{l}0,27 \\
0,23\end{array}$ \\
\hline $\begin{array}{l}\text { Todos los casos causados por RV ST2 } \\
\text { Casos puros causados por RV ST2 }\end{array}$ & $\begin{array}{l}15 \\
13\end{array}$ & $\begin{array}{l}9 \\
5\end{array}$ & $\begin{array}{l}40 \\
61\end{array}$ & $\begin{array}{l}0,22 \\
0,06\end{array}$ \\
\hline $\begin{array}{l}\text { Primer año } \\
(7 / 90-6 / 91):\end{array}$ & (160) & (157) & & \\
\hline $\begin{array}{l}\text { Todos los casos } \\
\text { Casos puros causados por RV }\end{array}$ & $\begin{array}{l}28 \\
23\end{array}$ & $\begin{array}{l}12 \\
11\end{array}$ & $\begin{array}{l}57 \\
51\end{array}$ & $\begin{array}{l}0,008 \\
0,03\end{array}$ \\
\hline $\begin{array}{l}\text { Todos los casos causados por RV ST1 } \\
\text { Casos puros causados por RV ST1 }\end{array}$ & $\begin{array}{l}20 \\
17\end{array}$ & $\begin{array}{l}9 \\
8\end{array}$ & $\begin{array}{l}55 \\
52\end{array}$ & $\begin{array}{l}0,03 \\
0,07\end{array}$ \\
\hline $\begin{array}{l}\text { Todos los casos causados por RV ST2 } \\
\text { Casos puros causados por RV ST2 }\end{array}$ & $\begin{array}{l}3 \\
3\end{array}$ & $\begin{array}{l}2 \\
2\end{array}$ & $\begin{array}{r}32 \\
0\end{array}$ & $\begin{array}{l}0,51 \\
0,98\end{array}$ \\
\hline $\begin{array}{l}\text { Segundo año } \\
\text { (7/91-6/92): }\end{array}$ & (203) & (204) & & \\
\hline $\begin{array}{l}\text { Todos los casos } \\
\text { Casos puros causados por RV }\end{array}$ & $\begin{array}{l}28 \\
23\end{array}$ & $\begin{array}{l}26 \\
18\end{array}$ & $\begin{array}{l}12 \\
22\end{array}$ & $\begin{array}{l}0,64 \\
0,40\end{array}$ \\
\hline $\begin{array}{l}\text { Todos los casos causados por RV ST1 } \\
\text { Casos puros causados por RV ST1 }\end{array}$ & $\begin{array}{l}12 \\
10\end{array}$ & $\begin{array}{l}15 \\
11\end{array}$ & $\begin{array}{l}0 \\
0\end{array}$ & $\overline{-}$ \\
\hline $\begin{array}{l}\text { Todos los casos causados por RV ST2 } \\
\text { Casos puros causados por RV ST2 }\end{array}$ & $\begin{array}{l}12 \\
11\end{array}$ & $\begin{array}{l}7 \\
7\end{array}$ & $\begin{array}{l}42 \\
37\end{array}$ & $\begin{array}{l}0,23 \\
0,33\end{array}$ \\
\hline
\end{tabular}

a Por análisis de la varianza.

${ }^{b}$ Las cifras entre paréntesis son los años-niño de vigilancia después de administrar tres dosis.

c ST1 = serotipo 1 del rotavirus G; ST2 = serotipo 2 del rotavirus G.

un período de 24 horas, respectivamente, en todos los episodios de diarrea causados por rotavirus; con respecto a este último resultado, los días de observación de quienes recibieron placebo y vacuna fueron de 1 a 10 $($ media $=4,3)$ y de 1 a 8 (media $=3,9)$, respectivamente. La vacuna también confirió una protección de $46 \%$ ( $P=$ $0,01)$ contra episodios de diarrea con una gravedad clínica (GC) calificada en 9 puntos y mostró cierta protección contra el vómito. En los episodios "puros" de diarrea por rotavirus se observó un buen grado de protección contra los vómitos $(41 \%$; $P=0,03)$; un MDL $\geq 6$ en 24 horas (59\%; $P=0,003)$; un $\mathrm{mDL} \geq 6$ por 24 horas $(65 \%$; $P=$ $0,02) ;$ y episodios con una GC de 9 puntos $(56 \% ; P<0,005)$.
Durante el primer año de seguimiento (cuadro 4), la vacuna confirió un grado significativo de protección contra el vómito $(52 \% ; P=0,04)$, contra un MDL $\geq 6$ en 24 horas $(59 \% ; P=0,02)$ y contra un $\mathrm{mDL} \geq 6$ en 24 horas $(84 \%$; $P=0,004)$ en todo tipo de diarrea causada por rotavirus. En episodios "puros" de diarrea causada por rotavirus, se observó un grado de protección significativo contra un MDL $\geq 6(60 \%$; $P=0,02)$ y un $\mathrm{mDL} \geq 6(82 \% ; P=0,01)$ en 24 horas.

No se observó ningún grado de protección significativo contra síntomas específicos en episodios de diarrea causados por rotavirus (ni en todos los casos en general ni en los episodios "puros") durante el segundo año de la vigilancia (cuadro 4). No obstante, la vacuna tuvo una eficacia protectora de $63 \%(P=0,01)$ contra episodios "puros" de diarrea de origen rotavírico con una GC calificada en 9 puntos (cuadro 4). La eficacia de la vacuna contra episodios de diarrea causados por rotavirus del serotipo 2 con una GC de 9 puntos fue de $91 \%(P=0,003)$.

\section{DISCUSIÓN}

La vacuna RRV-TV, administrada en una dosis de $4 \times 10^{4}$ ufp, fue bien tolerada por lactantes de 1 mes de edad y no se observó ningún aumento del vómito ni de la diarrea después de aplicar cualquiera de las dosis de la vacuna. Se observó una respuesta febril leve del tercer al quinto día, pero solo después de administrar la primera dosis. Estos resultados concuerdan con informes recibidos de Israel, Perú, Estados Unidos y Venezuela, según los cuales la misma dosis de la vacuna RRV-TV no causó efectos adversos o solo produjo reacciones febriles leves y pasajeras alrededor de cuatro días después de la inmunización $(10,14,17,19)$. Varios estudios posteriores en Estados Unidos y Venezuela en que se aplicó una dosis de vacuna de $4 \times 10^{5}$ ó de $4 \times 10^{6}$ ufp han dado resultados similares que confirman la inocuidad de la vacuna $(18,37)$.

En nuestro estudio la inmunogenicidad de la vacuna RRV-TV fue similar a la observada en otros estudios con la misma vacuna, o de sus elementos monovalentes, en países en desarrollo: en cerca de $60 \%$ de los lactantes se produjeron respuestas detectadas con ELISA para la detección de IgA y con la prueba de neutralización de RRV, mientras que solamente en 15 a 19\% de los lactantes se registraron anticuerpos contra el antígeno VP7 de los serotipos 1-4 del rotavirus $\mathrm{G}$ con la prueba de FRF $(9,19,35)$. Las respuestas de anticuerpos neutralizantes medidas con el ensayo de FRF son más frecuentes en lactantes de países desarrollados y ascienden a $50 \%$ cuando se trata de respuestas homotípicas a la vacuna monovalente del serotipo 1 de rotavirus $G(8,16)$. Entre los fenómenos que podrían explicar la menor inmunoge- 
CUADRO 3. Eficacia protectora de la vacuna tetravalente RRV contra los síntomas particulares en todos los casos de diarrea por rotavirus (RV) durante el seguimiento de 2 años (julio de 1990 a junio de 1992)

\begin{tabular}{|c|c|c|c|c|}
\hline $\begin{array}{c}\text { Episodios de diarrea } \\
\text { rotavírica }\end{array}$ & $\begin{array}{l}\text { Número tratado } \\
\text { con placebo }\end{array}$ & $\begin{array}{l}\text { Número tratado } \\
\text { con vacuna }\end{array}$ & $\begin{array}{l}\text { Porcentaje de } \\
\text { protección }\end{array}$ & $P^{\mathrm{a}}$ \\
\hline Dos años & $(363)^{b}$ & (361) & & \\
\hline \multicolumn{5}{|l|}{$\begin{array}{l}\text { Todos los episodios } \\
\text { causados por RV conc: }\end{array}$} \\
\hline $\mathrm{TR} \geq 8,0^{\circ} \mathrm{C}$ & 7 & 8 & 0 & - \\
\hline Vómito & 44 & 29 & 34 & 0,06 \\
\hline$M D L \geq 6$ & 34 & 18 & 47 & 0,02 \\
\hline $\mathrm{mDL} \geq 6$ & 19 & 8 & 58 & 0,03 \\
\hline Deshidratación & 6 & 4 & 33 & 0,53 \\
\hline CCS/hosp. & 28 & 22 & 21 & 0,40 \\
\hline $\mathrm{GC} \geq 9$ & 39 & 21 & 46 & 0,01 \\
\hline \multicolumn{5}{|l|}{$\begin{array}{l}\text { Episodios puros } \\
\text { causados por RV conc: }\end{array}$} \\
\hline $\mathrm{TR} \geq 38,0^{\circ} \mathrm{C}$ & 7 & 5 & 28 & 0,40 \\
\hline Vómito & 39 & 23 & 41 & 0,03 \\
\hline $\mathrm{MDL} \geq 6$ & 32 & 13 & 59 & 0,003 \\
\hline $\mathrm{mDL} \geq 6$ & 17 & 6 & 65 & 0,02 \\
\hline Deshidratación & 6 & 2 & 67 & 0,16 \\
\hline CCS/hosp. & 26 & 18 & 31 & 0,22 \\
\hline $\mathrm{GC} \geq 9$ & 34 & 15 & 56 & 0,005 \\
\hline
\end{tabular}

nicidad de la vacuna en los países en desarrollo figuran el posible efecto supresor de los anticuerpos maternos transmitidos por la leche de pecho o la placenta, o la posible competencia de otros virus entéricos. Aunque hay cada vez más pruebas de que los anticuerpos neutralizantes específicos contra VP7 no son el único mediador de inmunidad, la protección conferida por la vacuna sí muestra correlación con la seroconversión a anticuerpos de tipo IgA contra RRV detectados por ELISA (7). Esto ha llevado a distintos intentos por mejorar la inmunogenicidad y eficacia de la vacuna aumentando la dosis de la vacuna RRV-TV a $4 \times 10^{5}$ ufp (37).

A diferencia de lo expuesto hasta ahora, las tasas de seroconversión a anticuerpos específicos contra cada serotipo, determinadas con la prueba NRP, fueron mayores de $40 \%$ después de cualquiera de las dosis, porcentaje que se aproxima al observado en Venezuela (14). Los resultados de la
NRP también indican que siguió habiendo respuestas serológicas a los serotipos 1-4 de rotavirus $G$ después de la segunda y tercera dosis de la vacuna. Esta observación respalda la opinión de que un programa de inmunización de tres dosis mejora la inmunogenicidad de la RRV-TV.

En varios estudios se ha demostrado que la eficacia de las vacunas preparadas por recombinación genética de rotavirus aislados de monos rhesus y seres humanos a menudo es mayor en países desarrollados que en países en desarrollo. Por ejemplo, una sola dosis de la vacuna $\mathrm{D} \times \mathrm{RRV}$ (serotipo $1,1 \times$ $10^{4} \mathrm{ufp}$ ) confirió por un año un grado de protección de 67 a 77\% contra todos los episodios de diarrea de origen rotavírico (sobre todo del serotipo 1) en Finlandia y Estados Unidos, pero no en el Perú (7-9). Asimismo, tres dosis de la vacuna RRV-TV $\left(4 \times 10^{4} \mathrm{ufp} /\right.$ dosis) confirieron una protección de $57 \%$ por período de 1 año contra todos los episodios de diarrea causada por rotavirus en Estados Unidos, pero de solo $24 \%$ en el Perú $(18,19)$. Se notificaron diferencias geográficas similares en la eficacia de las vacunas orales preparadas con cepas de rotavirus vivos atenuados de origen bovino (37-40).

La eficacia de la vacuna RRV-TV que se ha observado en este estudio debe considerarse alentadora, más aún por el hecho de que la población estudiada reflejaba las malas condiciones socioeconómicas y la alta incidencia de enfermedades diarreicas típicas de muchos países en desarrollo. La protección contra todos los episodios de diarrea rotavírica fue de $57 \%$ durante el primer año de seguimiento y ascendió a más de $80 \%$ en enfermos con un promedio de seis o más deposiciones acuosas al día. Aunque no se observó mayor protección contra otros síntomas de la enfermedad en su forma más grave, esta apreciación sugiere que la vacuna es quizá un poco más eficaz contra los casos de enfermedad grave que contra los episodios de enfermedad en su totalidad. El fenómeno también se ha observado en otros ensayos efectuados con vacunas monovalentes o tetravalentes compuestas de rotavirus recombinantes procedentes de monos rhesus y seres humanos $(7,18,31)$. En este sentido la eficacia de la vacuna reviste particular importancia, ya que, en el contexto de la salud pública, el principal beneficio de una vacuna contra rotavirus sería su capacidad para prevenir casos de enfermedad graves y en ocasiones mortales. Los ensayos actuales que se concentran en los casos detectados en establecimientos de salud, en vez de en casos detectados por medio de visitas domiciliarias efectuadas con frecuencia, como las que se hicieron en el presente estudio, permitirían definir mejor el grado de protección conferido por la vacuna contra esos episodios.

La protección durante el segundo año de seguimiento fue mucho menor que durante el primero: $12 \%$ frente a $57 \%$ para todos los episodios de diarrea rotavírica. La protección conferida por la vacuna ha mostrado una disminución similar a lo largo del tiempo en algunos estudios en que se han usado vacunas obtenidas por 
CUADRO 4. Eficacia protectora de la vacuna tetravalente RRV contra síntomas particulares en casos de diarrea por rotavirus (RV) durante el primer año de seguimiento (7/90-6/91) y el segundo (7/91-6/92)

\begin{tabular}{|c|c|c|c|c|}
\hline $\begin{array}{c}\text { Episodios de diarrea } \\
\text { rotavírica }\end{array}$ & $\begin{array}{l}\text { Número tratado } \\
\text { con placebo }\end{array}$ & $\begin{array}{l}\text { Número tratado } \\
\text { con vacuna }\end{array}$ & $\begin{array}{l}\text { Porcentaje de } \\
\text { protección }\end{array}$ & $P^{a}$ \\
\hline Primer año & $(160)^{b}$ & (157) & & \\
\hline \multicolumn{5}{|l|}{$\begin{array}{l}\text { Todos los episodios } \\
\text { causados por RV conc: }\end{array}$} \\
\hline $\mathrm{TR} \geq 38,0^{\circ} \mathrm{C}$ & 3 & 4 & 0 & - \\
\hline Vómito & 21 & 10 & 52 & 0,04 \\
\hline$M D L \geq 6$ & 20 & 8 & 59 & 0,02 \\
\hline $\mathrm{mDL} \geq 6$ & 13 & 2 & 84 & 0,004 \\
\hline Deshidratación & 2 & 1 & 49 & 0,57 \\
\hline CCS/hosp. & 15 & 8 & 46 & 0,14 \\
\hline $\mathrm{GC} \geq 9$ & 17 & 9 & 46 & 0,11 \\
\hline \multicolumn{5}{|c|}{$\begin{array}{l}\text { Episodios puros causados } \\
\text { por RV conc: }\end{array}$} \\
\hline $\mathrm{TR} \geq 38,0^{\circ} \mathrm{C}$ & 3 & 3 & 0 & - \\
\hline Vómito & 17 & 9 & 46 & 0,11 \\
\hline$M D L \geq 6$ & 18 & 7 & 60 & 0,02 \\
\hline $\mathrm{mDL} \geq 6$ & 11 & 2 & 82 & 0,01 \\
\hline Deshidratación & 2 & 1 & 49 & 0,51 \\
\hline CCS/hosp. & 14 & 7 & 49 & 0,12 \\
\hline $\mathrm{GC} \geq 9$ & 14 & 8 & 42 & 0,20 \\
\hline Segundo año & $(203)^{b}$ & (204) & & \\
\hline \multicolumn{5}{|l|}{$\begin{array}{l}\text { Todos los episodios } \\
\text { causados por RV conc: }\end{array}$} \\
\hline $\mathrm{TR} \geq 38,0^{\circ} \mathrm{C}$ & 4 & 4 & 0 & - \\
\hline Vómito & 23 & 19 & 18 & 0,50 \\
\hline$M D L \geq 6$ & 14 & 10 & 29 & 0,39 \\
\hline $\mathrm{mDL} \geq 6$ & 6 & 6 & 0 & - \\
\hline Deshidratación & 4 & 3 & 25 & 0,70 \\
\hline CCS/hosp. & 13 & 14 & 0 & - \\
\hline$G C \geq 9$ & 21 & 12 & 43 & 0,09 \\
\hline \multicolumn{5}{|c|}{ Episodios puros causados } \\
\hline $\begin{array}{l}\text { por RV conc: } \\
T R \geq 38,0^{\circ} \mathrm{C}\end{array}$ & 4 & 2 & 50 & 0,34 \\
\hline Vómito & 21 & 14 & 34 & 0,21 \\
\hline$M D L \geq 6$ & 14 & 6 & 57 & 0,06 \\
\hline $\mathrm{mDL} \geq 6$ & 6 & 4 & 34 & 0,51 \\
\hline Deshidratación & 4 & 1 & 75 & 0,18 \\
\hline CCS/hosp. & 12 & 11 & 9 & 0,82 \\
\hline $\mathrm{GC} \geq 9$ & 19 & 7 & $63^{d}$ & 0,01 \\
\hline
\end{tabular}

a Por análisis de la varianza.

${ }^{b}$ Las cifras entre paréntesis son los años-niño de vigilancia después de administrar tres dosis.

c Véase la nota $c$ al pie del cuadro 3.

d Protección de $91 \%(P=0,003)$ contra el serotipo 2 del rotavirus.

recombinación genética de rotavirus aislados de monos rhesus y seres humanos (7), pero no en otros $(8,18)$. Ya que más de la mitad de los episodios de rotavirus detectados durante este estudio ocurrieron en el segundo año, es preciso tratar de prolongar la protección conferida por la vacuna, quizá aumentando el título del virus en cada dosis o aplicando una dosis de refuerzo al comienzo del segundo año de vida, o ambas cosas.

$\mathrm{Al}$ igual que en otros ensayos, en el presente estudio casi todos los episodios de diarrea por rotavirus fueron causados por el serotipo 1 del rotavirus $G$ y solamente se pudo demostrar un buen grado de protección contra este serotipo durante el primer año de seguimiento. El serotipo 2 del rotavi- rus $\mathrm{G}$ causó alrededor de un tercio de los episodios de diarrea por rotavirus, sobre todo durante el segundo año de seguimiento, y de ello surgió también el interrogante de si la eficacia reducida de la vacuna podría reflejar un menor grado de protección contra este serotipo del rotavirus G. Aunque los individuos vacunados mostraron una reducción de $42 \%$ de los episodios de diarrea causada por virus del serotipo 2 durante el segundo año, ese valor no fue estadísticamente significativo.

Los resultados de este ensayo deberían estimular el deseo de evaluar más a fondo la vacuna RRV-TV, especialmente en los países en desarrollo donde el rotavirus es la causa más importante de diarrea acuosa que pone en peligro la vida de lactantes y niños pequeños. Más importante aún sería hacer ensayos aumentando la dosis de vacuna a un mínimo de $4 \times$ $10^{5} \mathrm{ufp}$, a fin de lograr una mayor protección por más tiempo, y orientando el diseño principalmente hacia el estudio de la protección contra episodios de enfermedad grave $y$ de posible carácter mortal. Este tipo de ensayo está en marcha en Venezuela.

Agradecimiento. Este estudio fue apoyado por la División de Lucha contra las Enfermedades Diarreicas y las Infecciones Respiratorias Agudas de la OMS. Agradecemos a Claudio F. Lanata su asesoramiento en el diseño y análisis del estudio y sus observaciones y sugerencias sobre este manuscrito; a N. F. Pierce, Timo Vesikari, John Forro y Edward Zito, sus observaciones y comentarios críticos sobre este documento; y a S. Urasawa, G. Gerna, K. Wachsmuth y H. Fred Clark, su apoyo en los análisis de laboratorio. También reconocemos a Ana Huapaya y Veronilce B. da Silva por la asistencia prestada en el análisis de los datos. Por último agradecemos la colaboración de nuestro personal en el exterior, de los dirigentes comunitarios y de las autoridades de salud locales, que hicieron posible que se llevara a cabo este ensayo práctico. 
1. Institute of Medicine. The prospects of immunizing against rotavirus. En: New vaccine development: establishing priorities: II. Diseases of importance in developing countries. Washington, DC, National Academy Press, 1986:308-318 (Appendix D-13).

2. De Zoysa I, Feachem RG. Interventions for the control of diarrhoeal diseases among young children: rotavirus and cholera immunization. Bull World Health Org 1985; 63:569-583.

3. Bishop RF. Development of candidate rotavirus vaccines. Vaccine 1993;11:247-254.

4. Flores J, Kapikian A. Vaccines against rotavirus. En: Woodrow GC, Levine MM, eds. New generation vaccines. New York: Basel, Marcel Dekker; 1990. pp. 765-788.

5. Midthun K, et al. Reassortant rotaviruses as potential live rotavirus vaccine candidates. J Virol 1985,53:949-954.

6. Midthun K, et al. Single gene substitution rotavirus reassortants containing the major neutralization protein (VP7) of human rotavirus serotype 4. J Clinical Microbiol 1986; 24:822-826.

7. Vesikari T, et al. Protective efficacy against serotype 1 rotavirus diarrhea by live, oral rhesus-human reassortant rotavirus vaccines with human rotavirus VP7 serotype 1 or 2 specificity. Pediatr Infect Dis J 1992;11:535-542.

8. Madores HP, et al. Field trial of rhesus rotavirus reassortant vaccine of VP7 serotype 3 or 1 specificity in infants. J Infect Dis 1992; $166: 235-243$

9. Lanata $\mathrm{CF}$, et al. Immunogenicity, safety and protective efficacy of one dose of the rhesus rotavirus vaccine and serotype 1 and 2 human-rhesus rotavirus reassortants in children from Lima, Peru. Vaccine 1996;14: 237-243.

10. Dagan $R$, et al. Safety and immunogenicity of oral tetravalent human-rhesus reassortant rotavirus vaccine in neonates. Ped Infect Dis J 1992;11:991-996.

11. Flores J, et al. Reactions to and antigenicity of two human-rhesus rotavirus reassortant vaccine candidates of serotypes 1 and 2 in Venezuelan infants. J Clin Microbiol 1989,27: 512-518.

12. Halsey NA, et al. Human-rhesus reassortant rotavirus vaccine: safety and immunogenicity in adults, infants and children.J Infect Dis 1988;158:1261-1267.

13. Ing DJ, et al. Immunogenicity of tetravalent rotavirus vaccine administered with buffer and oral polio vaccine. Am J Dis Child 1991; 145:892-897.
14. Perez-Schael I, et al. Clinical studies of a quadrivalent vaccine in Venezuelan infants. Clin Microbiol 1990;28:553-558.

15. Tajima T, et al. Evaluation of a reassortant rhesus rotavirus vaccine in young children. Vaccine 1990;8:70-74.

16. Vesikari $\mathrm{T}$, et al. Immunogenicity and safety of rhesus-human rotavirus reassortant vaccines with serotype 1 or 2 VP7 specificity. Vaccine 1991;9:334-339.

17. Pichichero ME, et al. A comparative evaluation of the safety and immunogenicity of a single dose of unbuffered oral rhesus rotavirus serotype 3 , rhesus/human reassortant serotypes 1,2 , and 4 and combined (tetravalent) vaccines in healthy infants. Vaccine 1993;11:747-753.

18. Bernstein DI, et al. Evaluation of rhesus rotavirus monovalent and tetravalent reassortant vaccines in US children. I Amer Med Assoc 1995;273:1191-1196.

19. Lanata $C F$, et al. Safety, immunogenicity and efficacy of one or three doses of the rhesus tetravalent rotavirus vaccine in Lima, Peru. Vaccine 1992;10:273.

20. Lanata CF, Black RE. Guideline for design, conduct and analysis of community-based rotavirus vaccine field trials. Lima: Instituto de Investigación Nutricional; 1989. (Scientific Series Publication No. 1)

21. Linhares AC, et al. Acute diarrhoea associated with rotavirus among children living in Belém, Brazil. Trans R Soc Trop Med Hyg 1983; 77:384-390

22. Linhares AC, et al. Longitudinal study of rotavirus infection among children from Belém, Brazil. Epidemiol Infect 1989;102:129-146.

23. Linhares AC, et al. Epidemiology of rotavirus subgroups and serotypes in Belém, Brazil: a three-year study. Ann Inst Pasteur Virol 1988; 139:89-99.

24. World Health Organization. The management and prevention of diarrhoea: practical guidelines. $3^{\text {rd }}$ edition. Geneva: WHO; 1993.

25. Lennette $\mathrm{EH}$, et al., eds. Manual of clinical microbiology. $4^{\text {th }}$ edition. Washington, DC: American Society for Microbiology; 1985.

26. Flewett $\mathrm{TH}$, et al. Comparative evaluation of the WHO and DAKOPATTS enzyme-linked immunoassay kits for rotavirus detection. Bull World Health Org 1989;67:369-374.

27. Taniguchi K, et al. Direct serotyping of human rotavirus in stools by an enzyme-linked immunosorbent assay using serotype 1-, 2-, 3and 4-specific monoclonal antibodies to VP7. Infect Dis 1987:155:1159-1166.

28. Gerna G, et al. Characterization of serotypes of human rotavirus strains by solid-phase immune electron microscopy. J Infect Dis 1985; 152:1143-1151.

29. World Health Organization. Manual for laboratory investigations of acute enteric infections. Ginebra: WHO; 1987. (Documento inédito CDD/83.3 [Rev. 1]).

30. Levine MM, et al. Use of DNA probes and Hep-2 cell adherence assay to detect diarrheagenic Escherichia coli. J Infect Dis 1988;158: 224-228.

31. Garcia LS, et al. Techniques for recovery and identification of Cryptosporidium oocysts from stool specimens. J Clin Microbiol 1983;18: 185-190.

32. Bishop RF, et al. Estimation of rotavirus immunoglobulin $G$ antibodies in human serum samples by enzyme-linked immunosorbent assay: expression of results as units derived from a standard curve. J Clin Microbiol 1984;19:447-452.

33. Ward RL, et al. Effects of antibody to rotavirus on protection of adults challenged with a human rotavirus. J Infect Dis 1989;159: 79-88.

34. Bernstein DI, et al. Local and systemic antibody response to rotavirus WC3 vaccine in adult volunteers. Antiviral Res 1989;12: 293-300.

35. Offit PA, et al. Response of mice to rotaviruses of bovine or primate origin assessed by radioimmunoassay, radioimmunoprecipitation, and plaque reduction neutralization. Infect Immun 1983;42:293-300.

36. Flores J, et al. Protection against severe rotavirus diarrhoea by rhesus rotavirus vaccine in Venezuelan infants. Lancet 1987;1: 882-884.

37. Perez-Schael I, et al. Evaluation of the antigenicity and reactogenicity of varying formulations of the rhesus rotavirus-based quadrivalent and the M37 rotavirus vaccine candidates. J Med Virol 1994;42:330-337.

38. Vesikari T, et al. Protection of infants against rotavirus diarrhoea by RIT 4237 attenuated bovine rotavirus strain vaccine. Lancet 1984;1: 977-980.

39. Lanata CF, et al. Protection of Peruvian children against rotavirus diarrhea of specific serotypes by one, two, or three doses of the RIT 4237 attenuated bovine rotavirus vaccine. J Infect Dis 1989;159:452-459.

40. Raymond CA. Experimental rotavirus vaccine passes first test. Eventual goal: immunize newborns against most prevalent cause of life-threatening diarrhea. J Amer Med Association 1987;258:12-13. 
ABSTRACT A tetravalent rhesus-human reassortant rotavirus (RRV-TV) vaccine $\left(4 \times 10^{4}\right.$ plaqueforming units/dose) was evaluated for safety, immunogenicity and efficacy in a prospective, randomized, double-blind, placebo-controlled trial involving 540 Brazil-

Immunogenicity, safety and efficacy of tetravalent rhesushuman, reassortant rotavirus vaccine in Belém, Brazil ian infants. Doses of vaccine or placebo were given at ages, 1, 3 and 5 months. No significant differences were noted in the occurrence of diarrhoea or vomiting in vaccine and placebo recipients following each dose. Low-grade fever occurred on days 3-5 in $2-3 \%$ of vaccinees after the first dose, but not after the second or third doses of vaccine. An IgA antibody response to rhesus rotavirus (RRV) occurred in 58\% of vaccinees and $33 \%$ of placebo recipients. Neutralizing antibody responses to individual serotypes did not exceed $20 \%$ when measured by fluorescent focus reduction, but exceeded $40 \%$ when assayed by plaque reduction neutralization.

There were 91 cases of rotavirus diarrhoea among the 3-dose (vaccine or placebo) recipients during two years of follow-up, 36 of them among children given the vaccine. Overall vaccine efficacy was $8 \%(P=0.005)$ against any diarrhoea and $35 \%$ $(P=0.03)$ against any rotavirus diarrhoea. Protection during the first year of followup, when $\mathrm{G}$ serotype 1 rotavirus predominated, was $57 \%(P=0.008)$, but fell to $12 \%$ in the second year. Similar results were obtained when analysis was restricted to episodes in which rotavirus was the only identified pathogen. There was a tendency for enhanced protection by vaccine against illness associated with an average of 6 or more stools per day. These results are sufficiently encouraging to warrant further studies of this vaccine in developing countries using a higher dosage in an attempt to improve its immunogenicity and efficacy. 